\title{
The Determination of Partition Coefficient of 6-Mercaptopurine Derivatives by Thin Layer Chromatography
}

\author{
Andrzej Czyrski and Bartłomiej Kupczyk \\ Department of Physical Pharmacy and Pharmacokinetics, Poznań University of Medical Sciences, \\ 6 Świecickiego Street, 60-781 Poznań, Poland \\ Correspondence should be addressed to Andrzej Czyrski; aczyrski@ump.edu.pl
}

Received 14 June 2012; Revised 31 July 2012; Accepted 31 July 2012

Academic Editor: Irene Panderi

Copyright (C) 2013 A. Czyrski and B. Kupczyk. This is an open access article distributed under the Creative Commons Attribution License, which permits unrestricted use, distribution, and reproduction in any medium, provided the original work is properly cited.

Mercaptopurine and its derivatives are used in the treatment of leukemia. To estimate their lipophilicity, a simple and novel thin layer chromatography method was developed. The mobile phase was the mixture of acetonitrile and water. The acetonitrile content varied by $5 \%$ from $50 \%$ to $80 \%$. The linear relationship between $\log P$ and $R_{m 0}$ for substances with known lipophilicity was found. The lipophilicity of purine derivatives was worked out from the calibration curve. The most lipohilic compound was methylazathioprine (0.64).

\section{Introduction}

Lipophilicity describes the affinity of the compound to organic phase in a two-phase system of two immiscible liquids. The organic phase is a nonpolar solvent. The polar phase is water. Many biochemical, pharmacological, and toxicological processes involving the drug action strongly depend on lipophilicity $[1,2]$. The partition coefficient can be estimated by a classical shake-flask method. However, it has many disadvantages. For instance, it is time-consuming and requires relatively large amounts of solutes and solvents. Besides, the $\log P$ is limited to the range between -2 and +4 . It implies that this method cannot be applied to either very hydrophilic or very hydrophobic compounds [2-4].

In 1965, Boyce and Milborrow proved that retention factor $R_{m}$ is useful for determining the lipophilicity of the substances [5]. The shake-flask method was successfully replaced by the reversed-phase high-performance liquid chromatography (RP-HPLC) and the high-performance thin layer chromatography (RP-HPTLC). The TLC technique has many significant advantages. It is simple and less laborious. The amount of the sample of a substance is very small and it does not have to be very pure [5]. We established the linear relationship between the $\log P$ and $R_{m 0}$ value for the compounds with known lipophilicity [6]. This relationship exists whenever the separation mechanism is the partition of the analyte between mobile and stationary phases. Having determined the $R_{m 0}$ for the investigated compounds, we calculated the $\log P$ from the linear relationship for the compounds with known lipophilicity [7].

The analysed substances are 6-mercaptopurine (6-MP) and its derivatives, that is azathioprine (AZA), methylazathioprine (MAZA), and 6-metylmercaptopurine (6-MMP) (Figure 1). Azathioprine and 6-mercaptopurine are prodrugs widely used in the treatment of various diseases including acute lymphoblastic leukemia [8]. Azathioprine can be administered simultaneously with diclofenac in the treatment of patients with rheumatoid arthritis [9]. 6-methylmercaptopurine is a methylation product of 6mercaptopurine and it is inactive [8].

\section{Experimental}

2.1. Thin Layer Chromatography. The chromatographic separation of 6-MP, 6-MMP, AZA, and MAZA was carried out on HPTLC RP-18, F254s glass plates $(10 \times 10 \mathrm{~cm}$, Merck, Germany). The mixture of acetonitrile-water (v/v) was used as the mobile phase. The content of acetonitrile $(\mathrm{POCH}$, Gliwice, Poland) varied in 5\% increments from 50\% to 
<smiles>Sc1ncnc2[nH]cnc12</smiles><smiles>Cn1cnc([N+](=O)[O-])c1Sc1ncnc2[nH]cnc12</smiles>

3<smiles>CSc1ncnc2[nH]cnc12</smiles>

2<smiles>Cc1nc([N+](=O)[O-])c(Sc2ncnc3[nH]cnc23)n1C</smiles>

4

FIGURE 1: The structures of investigated compounds (6-MP 1, 6-MMP 2, AZA 3, and MAZA 4).

$80 \%$ [6]. All experiments were performed in the ambient temperature $\left(22 \pm 1^{\circ} \mathrm{C}\right)$.

The $1 \%$ solutions $(\mathrm{m} / \mathrm{v})$ of investigated compounds in methanol (POCH, Gliwice, Poland) were applied at the start line with a Hamilton syringe $(10 \mu \mathrm{L})$. The developed chromatograms were dried and the spots were visualized with $\mathrm{UV}_{254}$ light. The $R_{f}$ values were calculated by use of

$$
R_{f}=\frac{a}{b}
$$

where " $a$ " is the distance from baseline travelled by solute and " $b$ " is the distance from baseline travelled by solvent.

Their $R_{f}$ values were used to calculate the parameter $R_{m}$ according to Bate-Smith and Westal equation (2) [10]:

$$
R_{m}=\log \left(\frac{1-R_{f}}{R_{f}}\right)
$$

The $R_{m}$ values were extrapolated to an acetonitrile concentration of zero $\left(R_{m 0}\right)[11]$ by

$$
R_{m}=R_{m 0}+a C,
$$

where $C$ is the concentration of acetonitrile (\%,v/v) in the mobile phase. The value of the slope $(a)$ indicates the rate at which the solubility of the compound increases in the mobile phase [12].

2.2. The Calculation of Lipophilicity. The lipophilicity of the investigated compounds, expressed as the $\log P$, was calculated from

$$
\log P=B+a R_{m 0},
$$

TABLE 1: The $R_{m 0}$ values for investigated compounds.

\begin{tabular}{lcc}
\hline Compound & $R_{m 0} \pm \mathrm{SD}$ & RSD [\%] \\
\hline MAZA & $0.506 \pm 0.008$ & 1.58 \\
AZA & $0.263 \pm 0.008$ & 3.04 \\
6-MP & $0.433 \pm 0.037$ & 8.54 \\
6-MMP & $0.452 \pm 0.020$ & 4.42 \\
\hline
\end{tabular}

where $R_{m 0}$ is the $R_{m 0}$ value for a substance with known $\log P$; " $a$ " and " $B$ " are the slope and intercept, respectively. The regression equation was $\log P=1.265 R_{m 0}$. The $S_{a}$ value was 0.176 ; the intercept was not statistically significant.

All measurements were performed in triplicate. The precision was within the range $1,56-9,42 \%$. The method was linear $(r=0.998-0.999)$.

The compounds with known lipophilicity were isatin (Fluka, Germany), N-(2,6-dichlorophenyl)-acetamide m.p. $190-191^{\circ} \mathrm{C}$ (Medical University of Lublin, Poland), N-(2,4dichlorophenyl)-acetamide m.p. $141-142^{\circ} \mathrm{C}$ (Medical University of Lublin, Poland), 3,4-dichloroaniline (Aldrich, $\mathrm{UK}), 2$,6-dichloroaniline (Aldrich, UK), and p-nitrophenol (POCH, Gliwice, Poland) [13].

The $R_{m 0}$ for the above 6-mercaptopurine derivatives is calculated from (3). The $R_{m 0}$ and $\log P$ values are listed in Tables 1 and 2, respectively.

\section{Results and Discussion}

The main aim of this study was to determine the $\log P$ (logarithm of partition coefficient) values by the novel and simple thin layer chromatography method.

The experimental data revealed a linear relationship between $R_{m}$ and the concentration of the organic modifier (acetonitrile). The $R_{m}$ value decreases with the increase in 
TABle 2: The $\log P$ value for investigated compounds.

\begin{tabular}{lccc}
\hline Compound & $\log P$ & Milog $P^{\mathrm{a}}$ & $\operatorname{Alog} P^{\mathrm{b}}$ \\
\hline MAZA & 0.64 & 0.56 & 0.71 \\
AZA & 0.33 & 0.50 & 0.22 \\
6-MP & 0.55 & 0.34 & 0.52 \\
6-MMP & 0.57 & 0.54 & 0.64 \\
\hline${ }^{\mathrm{a}}$ [17], ${ }^{\mathrm{b}}[18]$. & & &
\end{tabular}

concentration of modifier in the mobile phase. In all cases, the TLC equations were linear. The intercepts $\left(R_{m 0}\right)$ in these equations can be considered as a measure of the partitioning compounds between the stationary phase and the mobile phase in $0 \%$ organic solvent. It can be considered as the balance between the interactions with the nonpolar phase and the interactions with the polar phase [12].

The methylated derivatives (MAZA and 6-MMP) are more lipophilic than AZA and 6-MP. The $\log P$ value for AZA is lower than the one for 6-MP (Table 2). It is caused by $-\mathrm{NO}_{2}$ group which is an electron-donor substituent. It decreases the lipophilicity of the compound [14]. It is caused by the presence of three additional nitrogen atoms and two oxygen atoms in AZA molecule. The AZA is a prodrug of 6-MP. AZA within two hours is transformed into 6-MP [15]. The removal of nitroimidazole ring from the AZA molecule results in the increase in the lipophilicity.

The introduction of the methyl group to AZA molecule results in the increase in the lipophilicity of MAZA. The increase in lipophilicity of MAZA makes it a new potential anticancer agent. In vitro studies on human cancer cells and in vivo studies in mice with transplanted cancer cells have confirmed this activity [16].

The $\log P$ values calculated by online software $[17,18]$ are similar to the ones determined empirically. However, some differences can be observed (Table 2). The experimental $\log P$ values are of the same order as the values of $\log P$ determined by software. The major difference is observed for AZA and 6-MP between the Milog $P$ (calculated $\log P$ based on group contribution) and the experimental data (Table 2). The Alog $P$ (the calculated $\log P$ based on atoms contribution) for 6-MP value is similar to the experimental one. However, Lucangioli et al. also observed similar situation for AZA. The experimental values of $\log P$ estimated by different techniques differed significantly from the one determined by the software (0.10-0.68 versus -0.54$)$ [19]. The differences between computational and experimental values for AZA, MAZA, and 6-MP were also observed by Hoffmann et al. [20].

\section{Conclusion}

The elaborated HP-TLC method is a novel one that enables us to determine the lipophilicity of the 6-MP derivatives. The results of the present study are in accordance with the values obtained from the software. However, the computational data cannot replace the experimental ones.

\section{Acknowledgments}

Professor Dariusz Matosiuk from the Medical University of Lublin is acknowledged for providing the samples of $\mathrm{N}-(2,4-$ dichlorophenyl)-acetamide and N-(2,6-dichlorophenyl)acetamide.

\section{References}

[1] M. Stefaniak, A. Niestrój, J. Klupsch, J. Śliwiok, and A. Pyka, "Use of RP-TLC to determine the log P values of isomers of organic compounds," Chromatographia, vol. 62, no. 1-2, pp. 87-89, 2005.

[2] D. Casoni and C. Sârbu, "Lipophilicity of some preservatives estimated by RP-TLC using stationary phases with different polarity," Chromatographia, vol. 70, pp. 1277-1282, 2009.

[3] D. Casoni, A. Kot-Wasik, J. Namieśnik, and C. Sârbu, "Lipophilicity data for some preservatives estimated by reversed-phase liquid chromatography and different computation methods," Journal of Chromatography A, vol. 1216, no. 12, pp. 2456-2465, 2009.

[4] A. Petruczynik, "Optimization of chromatographic systems for determination of lipophilicity for selected isoquinoline alkaloids," Journal of Liquid Chromatography and Related Technologies, vol. 32, no. 15, pp. 2265-2280, 2009.

[5] K. Jóźwiak, H. Szumiło, and E. Soczewiński, "Lipofilowość, metody oznaczania i rola w działaniu biologicznym substancji chemicznych," Wiadomości Chemiczne, vol. 55, pp. 1047-1075, 2000.

[6] A. Czyrski, T. Hermann, B. Rubiś, M. Rybczyńska, and D. Śledź, "Biopharmaceutical characterization of some new papaverine decomposition products," Pharmazie, vol. 66, no. 3, pp. 165-167, 2011.

[7] K. Mazák, J. Vámos, A. Nemes, Á. 叉. Rácz, and B. Noszál, "Lipophilicity of vinpocetine and related compounds characterized by reversed-phase thin-layer chromatography," Journal of Chromatography A, vol. 996, no. 1-2, pp. 195-203, 2003.

[8] M. Milek, N. K. Kuzelicki, A. Smid, and I. Mlinaric-Rascan, "S-adenosylmethionine regulates thiopurine methyltransferase activity and decreases 6-mercaptopurine cytotoxicity in MOLT lymphoblasts," Biochemical Pharmacology, vol. 77, no. 12, pp. 1845-1853, 2009.

[9] F. Główka, M. Karaźniewicz-Łada, E. Grześkowiak, D. Rogozinska, and W. Romanowski, "Clinical pharmacokinetics of ketoprofen enantiomers in wild type of Cyp 2c8 and Cyp 2c9 patients with rheumatoid arthritis," European Journal of Drug Metabolism and Pharmacokinetics, vol. 36, no. 3, pp. 167-173, 2011.

[10] M. L. Bieganowska, A. Doraczynska-Szopa, and A. Petruczynik, "The retention behavior of some sulfonamides on different TLC plates. 2. Comparison of the selectivity of the systems and quantitative determination of hydrophobicity parameters," Journal of Planar Chromatography, vol. 8, no. 2, pp. 122-128, 1995.

[11] F. L. Andrić, J. T. Trifković, A. D. Radoičić et al., "Determination of the soil-water partition coefficients (logKOC) of some mono- and poly-substituted phenols by reversed-phase thin-layer chromatography," Chemosphere, vol. 81, no. 3, pp. 299-305, 2010.

[12] G. L. Biagi, A. M. Barbaro, A. Sapone, and M. Recanatini, "Determination of lipophilicity by means of reversed-phase 
thin-layer chromatography. I. Basic aspects and relationship between slope and intercept of TLC equations," Journal of Chromatography A, vol. 662, no. 2, pp. 341-361, 1994.

[13] C. Hansch, A. Leo, and D. Hoekman, Exploring QSAR Hydrophobic, Electronic and Steric Constants, Professional Reference Book, ACS, Washington, DC, USA, 1995.

[14] G. Thomas, Medicinal Chemistry an Introduction, John Wiley \& Sons Ltd, New York, NY, USA, 2000.

[15] S. Sahasranaman, D. Howard, and S. Roy, "Clinical pharmacology and pharmacogenetics of thiopurines," European Journal of Clinical Pharmacology, vol. 64, no. 8, pp. 753-767, 2008.

[16] B. Hładoń, W. Gutsche, S. Bałoniak, and H. Sikorska, "Experimental antitumor activity of new azathioprine analogues," Arzneimittel Forschung, vol. 39, pp. 78-81, 1989.

[17] 2012, http://www.molinspiration.com/services/logp.html.

[18] 2012, http://www.vcclab.org/.

[19] S. E. Lucangioli, E. Kenndler, A. Carlucci, V. P. Tripodi, S. L. Scioscia, and C. N. Carducci, "Relation between retention factors of immunosuppressive drugs in microemulsion electrokinetic chromatography with biosurfactants and octanolwater partition coefficients," Journal of Pharmaceutical and Biomedical Analysis, vol. 33, no. 5, pp. 871-878, 2003.

[20] M. Hoffmann, M. Chrzanowska, T. Hermann, and J. Rychlewski, "Modeling of purine derivatives transport across cell membranes based on their partition coefficient determination and quantum chemical calculations," Journal of Medicinal Chemistry, vol. 48, no. 13, pp. 4482-4486, 2005. 

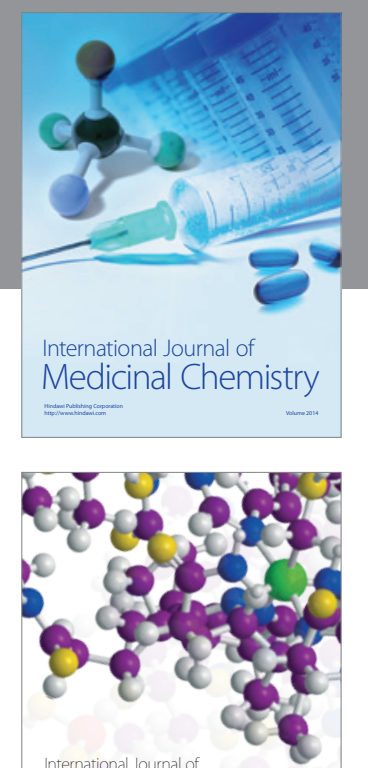

\section{Carbohydrate} Chemistry

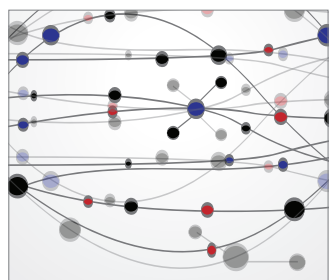

The Scientific World Journal
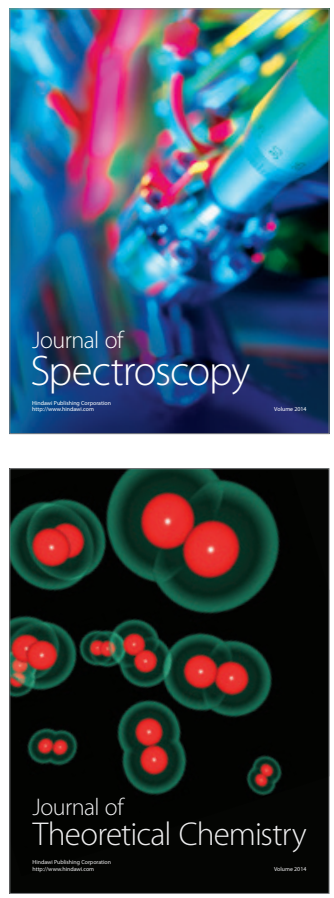
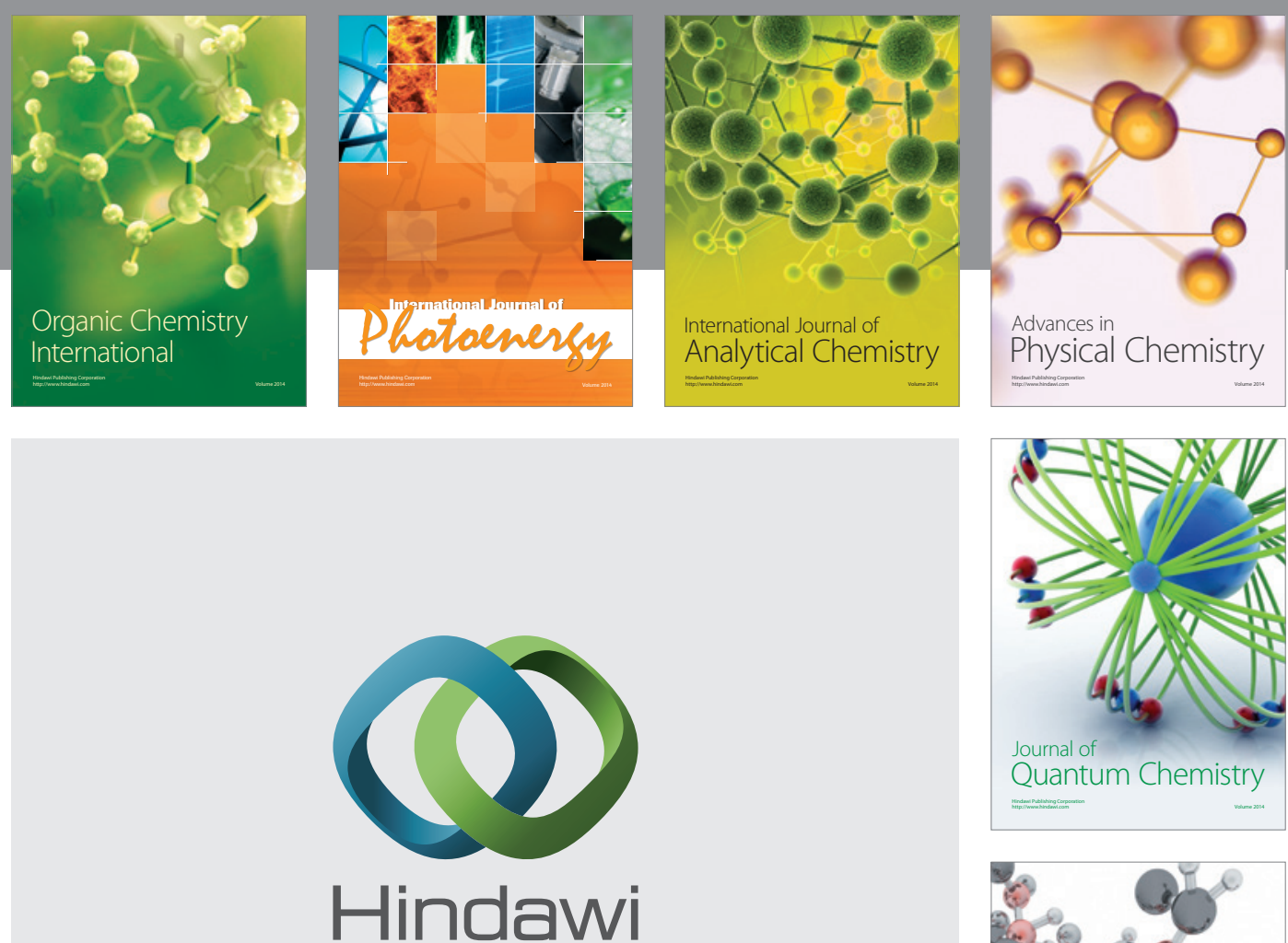

Submit your manuscripts at

http://www.hindawi.com

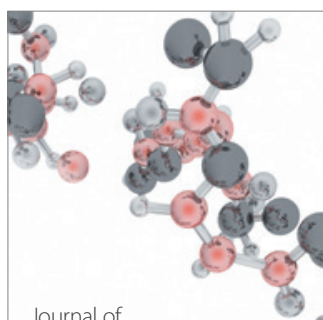

Analytical Methods

in Chemistry

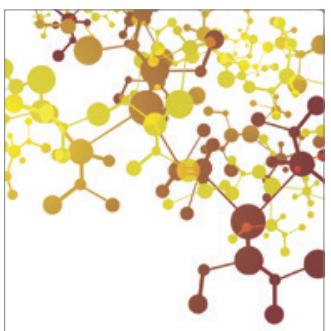

Journal of

Applied Chemistry

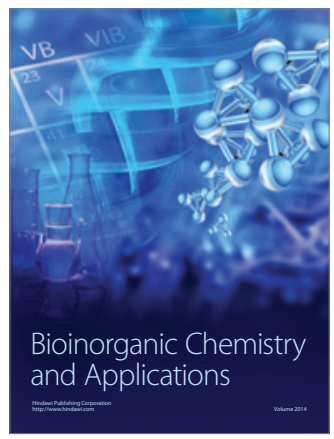

Inorganic Chemistry
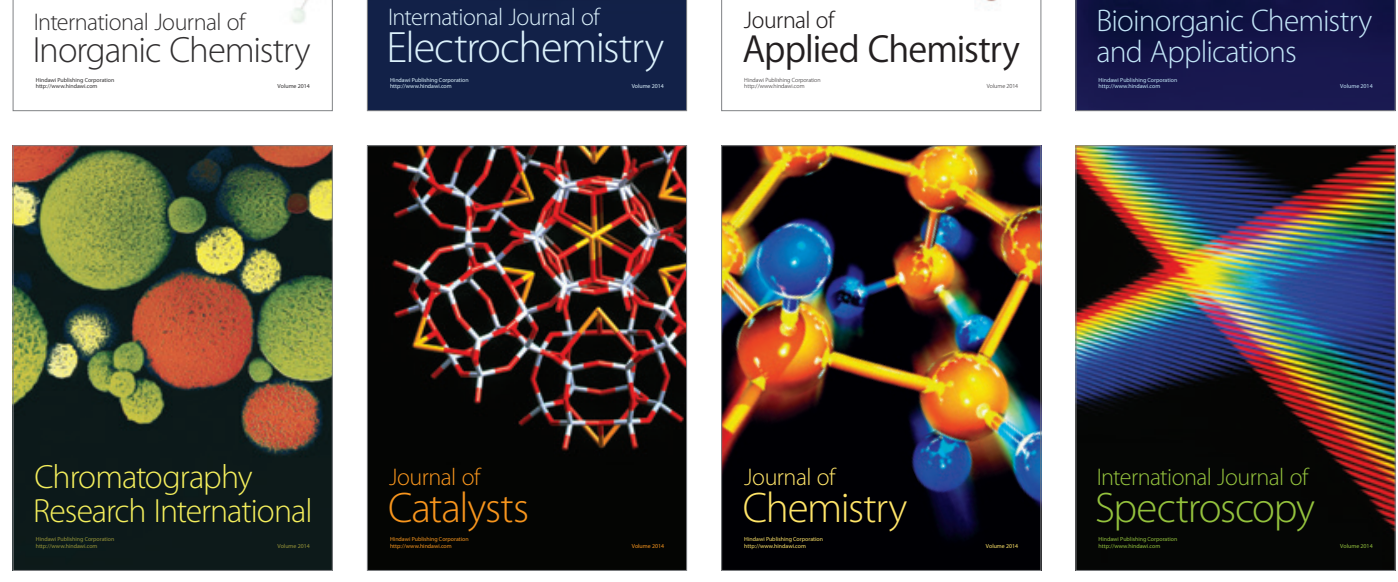